\title{
Post-operative maxillary cyst related to LeFort I osteotomy: Case report
}

\author{
Dong-Uk Seo ${ }^{1}$, Su-Gwan Kim ${ }^{1,2 *}$, Ji-Su Oh ${ }^{1,2}$, Jae-seek You ${ }^{1,2}$, and Bo-Su Shin ${ }^{1}$ \\ ${ }^{1}$ Deparment of Oral and Maxillofacial Surgery, School of Dentistry, Chosun University, Gwangju 61452, Republic of Korea \\ ${ }^{2}$ Oral Biology Research Institute, Chosun University, Gwangju 61452, Republic of Korea
}

(Received Jun 9, 2017; Revised version received Aug 30, 2017; Accepted Aug 31, 2017)

\begin{abstract}
Post-operative maxillary cysts are locally aggressive lesions that typically develop as delayed complications many years after a CaldwellLuc operation. This report describes a case of post-operative maxillary cysts following a LeFort I osteotomy performed approximately 7 years ago. The patient complained of stinging pain on her left cheek. Radiographic examination revealed a radiolucency lesion on the left maxillary sinus with a well-defined margin and bone destruction. The cysts were enucleated with the removal of metal plates and screws for pain relief. A histopathological examination confirmed the diagnosis of post-operative maxillary cysts. The patient has remained asymptomatic thus far, and there was no evidence of local recurrence at the 3-year postoperative follow-up.
\end{abstract}

KEY WORDS: Complication, Jaw cysts, Orthognathic surgery

\section{서 론}

술 후 상악 낭종(Postoperative maxillary cyst)은 1927년 Kubo에 의해 처음 보고되었으며, 외과적 섬모 낭종(surgical ciliated cyst) 또는 부비 낭종(paranasal cyst)라고도 알려져 있다[1]. 이는 중안면골의 절골술, Caldwell-Luc 시술, 상 악동의 기저부를 들어올리는 수술 등 상악동을 포함하는 수술 후 또는 중안면골의 골절이나 총상 등의 외상 후에 지연성 합병증으로 나타날 수 있다[2]. 이 낭종은 국소적 으로 공격적일 수 있으며 단방성이나 다방성으로 나타나 고 임상적으로 협측부위에 부종과 동통을 수반하며 상악 과 상악 치아에 불편감을 나타낸다[3]. 술 후 상악 낭종의 진단은 조직학적 소견뿐 아니라 상악동 관련 수술 또는 외 상의 기왕력 및 방사선학적 소견 임상적 소견을 종합하여 이루어진다.

1990년에 Sugar 등[4]은 중안면골의 악교정 수술 시행 후 술 후 상악 낭종이 발생한 증례를 보고하였고, 1993년

\footnotetext{
*Corresponding author: Su-Gwan Kim

Department of Oral and Maxillofacial Surgery, School of Dentistry, Chosun University, 309 Pilmun-daero, Dong-gu, Gwangju 61452, Republic of Korea Tel.: +82-62-220-3815, Fax: +82-62-228-7316

E-mail: sgckim@chosun.ac.kr
}

Hayhurst 등[5]도 악교정 수술 후 발생한 술 후 상악 낭종 에 대해 보고하였다. 이 증례들에서 술 후 상악 낭종은 악 교정 수술 시행 후 3에서 7년 후에 상악이나 경구개 부위 에서 발생하였다.

본 증례는 31 세 남환으로 하악골 전돌증 및 안면 비대 칭을 주소로 LeFort I 골절단술과 양측 하악골 상행지 시 상 분할 골절단술을 시행하고 7년이 경과한 후 좌측 상악 동에 술 후 상악 낭종이 발생하였으며, 이를 문헌고찰과 함께 보고하고자 한다.

\section{증례 보교}

31 세의 환자가 왼쪽 안면부의 부종 및 간헐적으로 발생 하는 통증을 주소로 내원하였다. 내원하기 1년 전에 환자 는 치과의원에서 좌측 제 1 대구치의 아말감 수복 치료를 받았으며, 지난 6 개월 간 반복되는 통증으로 개인치과를 내원하다 조선대학교 치과병원 구강외과로 의뢰되었다.

초진 임상검사 결과 좌측 상악 제1대구치 전정부 점막 의 종창을 보였으며 촉진시 통증을 호소하였다. 전기치수 검사에서 좌측 상악 제1대구치는 양성 반응을 보였으며, 환자는 예통을 호소했다. 파노라마 영상에서는 좌측 상악 견치에서 제 1 대구치부위까지 경계가 불분명한 방사선투과 
상이 관찰되었다(Fig. 1). Computed tomography(CT)상에 서는 경계가 뚜렷한 낭성 병소가 관찰되었으며, 주변골의 팽창 및 비박, 천공이 확인되었다(Fig. 2).

7년전에 안면 비대칭 및 하악 전돌증의 개선을 위해 LeFort I 골절술과 양측성 하악골 상행지 시상분리골절술 (BSSRO)을 시행받은 과거력이 있었으며, 비염이나 축농 증의 진단이나 치료에 대한 기왕력은 없었다. 술후 상악 낭종(postoperative maxillary cyst)으로 잠정적으로 진단하 고 적출술을 계획하였다. 전신마취하에서 좌측 상악 전치

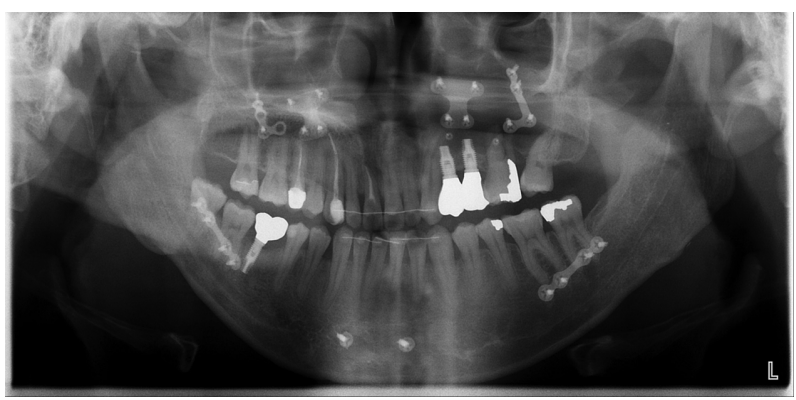

Fig. 1. Ill-defined radiolucency between $\# 23$ and $\# 26$ was shown in panoramic view.
부에서 구치부 후방까지 연장된 수평 점막 절개를 통해서 상악동의 전외측벽을 노출시키기 위해 점막골막피판을 거 상하였다. 병소부위의 피질골 천공이 관찰되었고, 피질골 비박 및 팽창이 확인되었다. 큰 골창을 형성하여 병소에 접근하였다. 두꺼운 벽을 가진 단방성의 낭종이 녹색을 띈 점액과 함께 노출되었고(Fig. 3), 낭종의 벽은 부분적으로

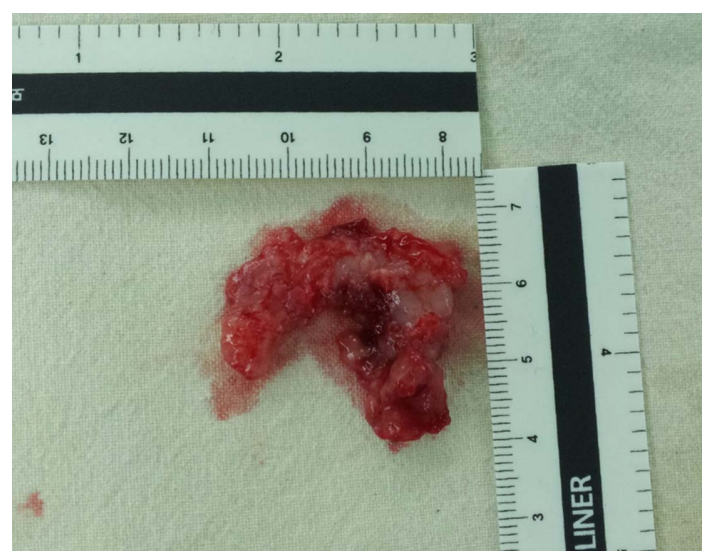

Fig. 4. The lesions measured approximately $30 \mathrm{~mm} \times 30 \mathrm{~mm}$.

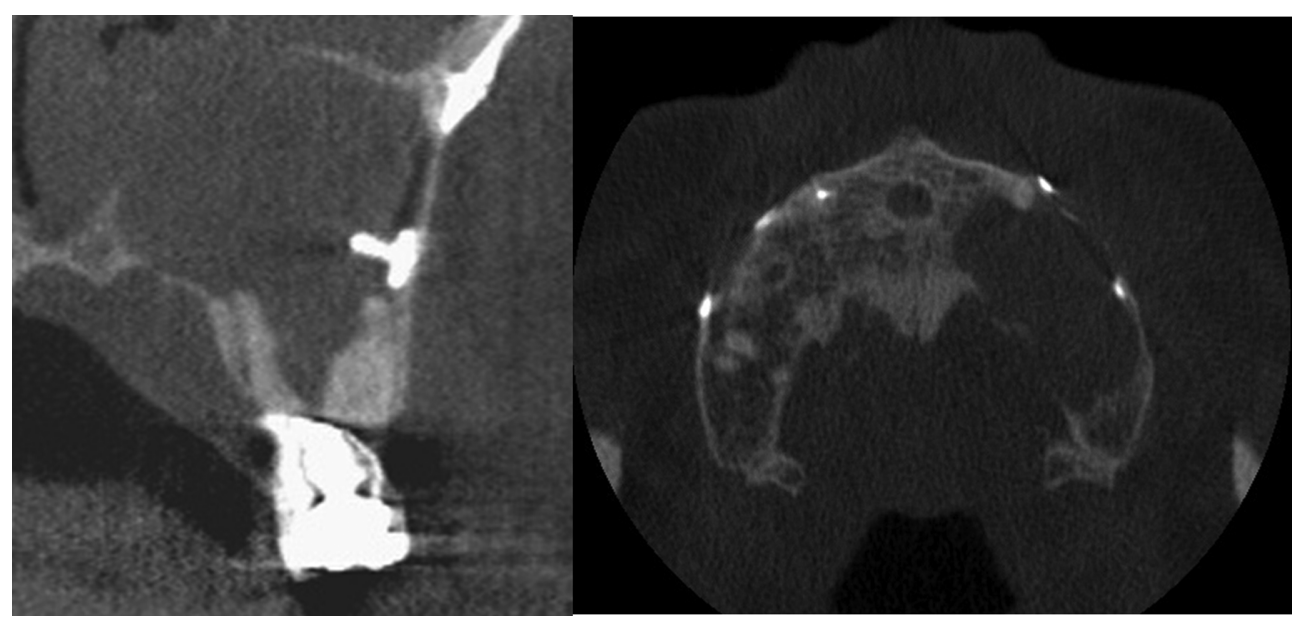

Fig. 2. Buccal and palatal cortical bone perforation was shown in CT images.
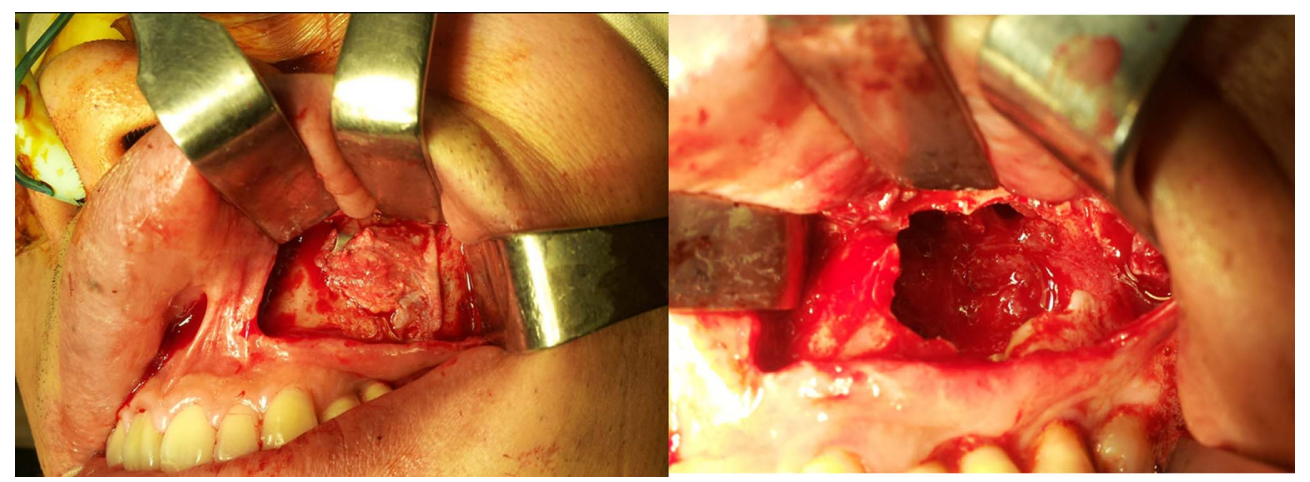

Fig. 3. Photographic view of intra-operation. Revealing a thick unilocular cyst which had displaced the floor of the maxillary sinus superiorly. 


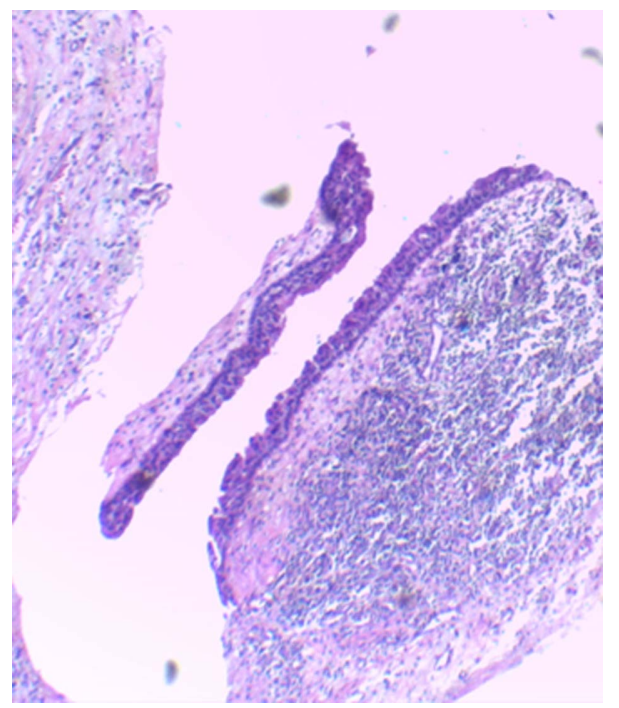

Fig. 5. The respiratory epithelium was observed.

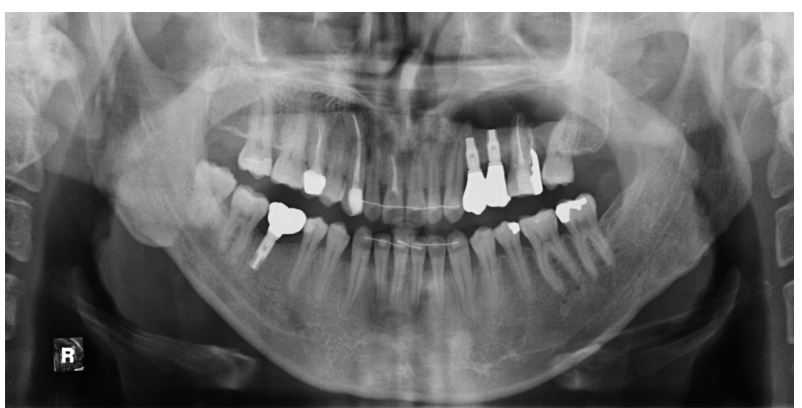

Fig. 6. There was no evidence of recurrence 3years after enucleation.

상악동 막에 붙어있었다. 정상조직과 분리 후 낭종은 완전 히 제거되었다(Fig. 4). 조직병리학적 검사상respiratory epithelium과 squamous epithelium으로 이장되어 있는 술 후 상악 낭종(postoperative maxillary cyst)으로 진단되었다 (Fig. 5). 술 후 3년간 재발 등의 이상 소견 없이 양호한 회 복을 보였다(Fig. 6).

\section{고 찰}

술 후 상악 낭종의 발병은 상악동의 외과적인 수술 후 에 상악동 점막의 잔여물이 수술부위로 함입되거나, 상악 동이 재생성 육아조직으로 완전히 채워지기 이전에 상악 동구가 조기 폐쇄 되는 것이 그 기전으로 보고되었다[3]. LeFort I 골절단술 시행 후 발생하는 술 후 상악 낭종은 골 절단술시에 상악동의 점막이나 비강 점막, 혹은 비구개관 의 점막에 손상이 발생하고, 이러한 점막이 골절단술을 시 행한 절단면 사이로 들어가 낭종성 변화가 일어나 발생하
는 것으로 여겨지고 있으나 왜 점막 상피가 낭종성 변화 를 일으키는지는 밝혀지지 않고 있다[4]. Hayhurst 등 [5]이 보고한 사례에서도 비점막의 작은 단편이 상악 골절단면 사이에 갇히고, 수년 후에 낭성 변성이 일어난 것으로 추 정하였으며 따라서 비점막을 보존하고 비점막 천공이 발 생했을 경우 이의 처치가 중요하다고 하였다.

악교정 수술 후 발생하는 술 후 상악 낭종을 예방하는 명확한 방법은 정립되지 않았지만, LeFort I 골절단술 시 상악동의 염증성 호흡 점막을 완전히 제거하고, 출혈을 최 소화 하며, 상악동 내에 혈종이 생기지 않도록 하고, 상악 동구의 폐쇄를 예방하고 주위 조직의 자극을 피하는 등의 방법이 필요하다[4,6]. 하지만 술자가 위에서 언급된 요인 들에 대해 주의를 기울이더라도 상악동에서 술 후 상악낭 종의 발생을 완전히 막는 것은 어렵다.

술 후 상악 낭종과 감별을 요하는 질환으로는 종양성 병 소, 재발성 상악동염, 상악동내의 점액 낭종, 치근단 낭종, 비 구개관 낭종 등이 있을 수 있다[2,7]. 이런 질환들과의 감 별을 위해서는 임상적 방사선학적 평가와 기왕력에 대한 평가가 필요하다. 파노라마와 Water's 방사선 사진이 상악 동 질환들을 발견하는 데 이용될 수 있는데 방사선사진상 술 후 상악 낭종은 단방성 또는 다방성의 경계가 비교적 명확한 소견을 보이지만 경계가 명확하지 않은 경우도 있 다[8]. CT 촬영을 통해 이 병소에 대해 보다 더 정확한 방 사선적 평가를 할 수 있다[9].

술후 상악 낭종의 처치는 일반적으로 본 증례처럼 낭종 의 완전한 적출과 일차 봉합이다[3]. 동시에 상악동 천공 술(nasal antrostomy)역시 추천되며, 얇은 낭종 벽을 가지 고 광범위한 피질골 천공이 동반된 단방성의 낭종에 있어 서는 조대술이 추천된다[6]. 본 증례에서는 술 후 3 년간 재 발 소견 없이 양호한 회복을 보였으며, Yoshikawa 등[6]은 부적절한 적출시 재발률을 높일 수 있다고 하였다.

비록 술 후 상악 낭종이 상악의 악교정 수술 이후에 아주 드물게 발생하지만 지연된 진단을 피하기 위해서 각종 상악 동 수술과 외상 뿐 아니라 악교정 수술을 받은 환자에서 증 상을 호소할 시 감별진단에 포함하고 $\mathrm{CT}$ 촬영 등을 시행하 여 신속한 진단 및 처치를 해야 할 것으로 생각된다.

\section{Conflict of Interest}

The authors declare that they have no competing interests.

\section{ORCID}

Dong-Uk Seo 0000-0002-4188-846X 
Dong-Uk Seo et al.

\author{
Su-Gwan Kim $\quad$ 0000-0002-0424-9984 \\ Ji-Su Oh 0000-0002-8369-5025 \\ Jae-seek You 0000-0001-7638-9583 \\ Bo-Su Shin 0000-0001-9140-6345
}

\section{References}

1. Gregory GT, Shafer WG. Surgical ciliated cysts of the maxilla: report of cases. J oral Surg 1958;16:251-253.

2. Amin M, Witherow H, Lee R, Blenkinsopp P. Surgical ciliated cyst after maxillary orthognathic surgery: report of a case. J Oral Maxillofac Surg 2003;61:138-141. doi: 10.1053/joms.2003.50050.

3. Kaneshiro S, Nakajima T, Yoshikawa Y, Iwasaki H, Tokiwa N. The postoperative maxillary cyst: report of 71 cases. J Oral Surg 1981;39:191-198.

4. Sugar AW, Walker DM, Bounds GA. Surgical ciliated (postoperative maxillary) cysts following mid-face osteotomies. Br J Oral Maxillofac Surg 1990;28:264-267. doi: 10.1016/0266-4356(90)90064-R.

5. Hayhurst DL, Moenning JE, Summerlin DJ, Bussard DA. Surgical ciliated cyst: a delayed complication in a case of maxillary orthognathic surgery. J Oral Maxillofac Surg 1993;51:705-708.

6. Yoshikawa Y, Nakajima T, Kaneshiro S, Sakaguchi M. Effective treatment of the postoperative maxillary cyst by marsupialization. J Oral Maxillofac Surg 1982;40:487491. doi: 10.1016/0278-2391(82)90009-X.

7. Raine C, Williamson SL, McLean NR. Mucous cyst of the alar base: a rare complication following rhinoplasty. Br J Plast Surg 2003;56:176-177. doi: 10.1016/S00071226(03)00029-8.

8. Michael BP, Sano K, Kitamura A, Inokuchi T. Computed tomography in the evaluation of postoperative maxillary cysts. J Oral Maxillofac Surg 1990;48:679-684. doi: 10.1016/0278-2391(90)90049-8.

9. Heo MS, Song MY, Lee SS, Choi SC, Park TW. A comparative study of the radiological diagnosis of postoperative maxillary cyst. Dentomaxillofac Radiol 2000;29:347351. doi: $10.1038 / \mathrm{sj} / \mathrm{dmfr} / 4600552$. 